\title{
THEORETICAL ANALYSIS OF THE DEFINITION OF "ASSURANCE OF QUALITY OF VOCATIONAL TRAINING" FOR FUTURE SECONDARY EDUCAITON MASTERS IN PHYSICAL CULTURE
}

\section{ТЕОРЕТИЧНИЙ АНАЛІЗ ДЕФІНІЦІЇ "ЗАБЕЗПЕЧЕННЯ ЯКОСТІ ПРОФЕСІЙНОӦ ПІДГОТОВКИ" ДЛЯ МАЙБУТНІХ МАГІСТРІВ СЕРЕДНЬОЇ ОСВІТИ 3 ФІЗИЧНОЇ КУЛЬТУРИ}

Yuriy DUTCHAK, candidate of science in physical education and sports, associate professor

https://orcid.org/0000-0003-0537-2316 yrdutchak@ukr.net

Oleg KVASNYTSIA, Candidate of science in physical education and sports

https://orcid.org/0000-0003-2478-915X

$$
\text { oleg.kvasnitsa@ukr.net }
$$

Khmelnytsky National University

$\triangle 11$ Institutskaya St., Khmelnitske, 28000
Юрій ДУТЧАК, кандидат наук з фізичного вихованні і спорту, доцент

Original manuscript received: October 01, 2019

Revised manuscript accepted: December 11, 2019

\section{ABSTRACT}

Assurance of quality of vocational training of future specialists (professionals) is an urgent issue which is stipulated by various factors, among which assurance of quality of the aim, quality of educational process, and quality of the result have been distinguished. Under given conditions, understanding of basic notions of research is very important.

The aim of the article is to theoretically analyze definition of "assurance of quality of vocational training" for future secondary educaiton masters in physical culture.

Methods of research: analysis of scientific references and document; method of systematic analysis; method of comparison and juxtaposition; method of functional and structural analysis.

To substantiate the definition of "assurance of quality of vocational training" for future secondary educaiton masters in physical culture, we assume reasonable to reveal the essence of the following key notions: "quality", "quality of education", "quality of higher education".

The mnotion of "quality of educaiton" is viewed by us as a complex characteristics of 
educaitonal process that envisages balanced accordance of the process, result, and educational system with the aim, needs, and social standards of education with the aim to form and develop person's intellect, manners, and certain social, psychological, physical, and spiritual features that are realized at certain stages of education.

Interpretation of the notion of "assurance of quality" established by European Center for the Development of Vocational Training, in standards and recommendations to assurance of quality in European Union higher educational plane has been analyzed. Dublin model of universal characteristics (Dublin Descriptors) of graduate's competences has been described.

We assume reasonable to state that assurance of the quality of vocational training of future secondary education masters in physical culture is a totality of procedures and activity whose aim is to ensure and improve efficiency of giving educational services that envisage formation of special knowledge, teaching physical exercises, development of physical skills, and education of moral and willpower qualities of a person, which corresponds to demands of the state and interested parties (stakeholders).

Key words: quality, quality of education, quality of higher education, assurance of quality of vocational training of future secondary education masters in physical culture.

Вступ. Долучення нашої держави до Болонського процесу, в якому основоположною $€$ проблема забезпечення якості підготовки фрахівців, що обумовлюється зростанням масовості у вищій освіті; зацікавленістю роботодавців у якісній підготовці фахівців; зменшенням обсягу державного фінансування вищої освіти з одночасною вимогою щодо ефрективності витрат отриманих закладами вищої освіти коштів; підвищенням вимог суспільства до прозорості та відкритості діяльності університетів; формуванням конкурентного середовища серед університетів, висуває нові вимоги до організації освітнього процесу в закладах вищої освіти.

Забезпечення якості професійної підготовки майбутніх фахівців (професіоналів) обумовлюється різними факторами, серед яких виділяються забезпечення якості мети, якості освітнього процесу і якості результату. У таких умовах принципове значення має інтерпретація понять, що є базовими в дослідженні.

Обґрунтування наукової теорії, як відзначає В. Столяров, пов'язане з потребою уточнення слів, що в ній використовуються і взяті зі звичайної мови, та з визначенням надійних критеріїв відмінностей, специфіки об'єктів пізнання, зумовлює потребу вивчення логічного прийому, відомого під назвою "дефініція" (Столяров, 2015: 134-135). У Сучасному словнику іншомовних слів (Скопенко, 2006: 158) слово "дефрініція" походить від латинського "defininito", що перекладається як "визначення", і означає визначення якого-небудь поняття, яке відображає його істотні ознаки.

У процесі введення та використання нових дефініцій можуть виникнути проблеми, пов'язані, в першу чергу, із суб'єктивізмом дослідника. 3 метою усунення означеного В. Столяров запропонував “логіко-методологічну технологію визначення понять, яка передбачає дотримання трьох основних принципів: урахування ефективності 
визначень; розмежування змістовного $і$ термінологічного аспектів $i$ відповідних проблем визначення; необхідність введення та аналізу не одного поняття, а системи понять, важливих для виокремлення та дифреренціації різних об'єктів, які вивчають" (Столяров, 2015: 203). Використання вказаної технології видається доцільним під час обґрунтування визначень, що стосуються забезпечення якості професійної підготовки майбутніх магістрів середньої освіти з фрізичної культури.

Мета статті - здійснити теоретичний аналіз дефініції “забезпечення якості професійної підготовки” для майбутніх магістрів середньої освіти з фрізичної культури.

Методи дослідження: аналіз літературних джерел та документів; метод системного аналізу; метод порівняння і зіставлення; метод функціонально-структурного аналізу.

Результати та дискусії. Для обґрунтування дефініції “забезпечення якості професійної підготовки" для майбутніх магістрів середньої освіти з фізичної культури вважаємо за доцільне з'ясувати сутність понять "якість", "якість освіти", "якість вищої освіти", які $\epsilon$ ключовими для вказаного визначення.

Л. Шипіліною категорія “якість" розглядається як сукупність властивостей певного суб'єкта чи об'єкта (сутнісний аспект); систему якісних та кількісних характеристик або частин об'єкта чи процесу (аспект структурності); поєднання змінних та темпоральних характеристик (аспект динамічності); сутнісна визначеність, яка може виявлятися в закономірному зв'язку складових частин та елементів (аспект визначеності); основа існування об'єкта чи процесу, яка виявляється через категорії властивості, кількості, змінності тощо (аспект зовнішньої та внутрішньої обумовленості); цінність людського буття, створюваних людиною та людством систем, механізмів, процесів тощо (аксіологічний аспект) ( Шипилина, 2007: 47).

Досліджуючи категорію “якість", В. Кардаш, І. Павленко та О. Шафалюк визначають "чотири ї̈ сутmєві аспекти, що є важливими для розуміння сутності. По-перше, ототожнювання якості з властивостями продукції дає змогу розглядати ї як найскладнішу властивість. По-друге, якість як певна иілісність і завершеність споживчої вартості існує лише за існування потреби в продукції. По-третє, не всі властивості продукції визначають ї якість. Підвищення якості здійснюється за рахунок поліпшення не всіх, а лише корисних властивостей продукції, котрі забезпечують виконання або розширення основних їі функцій. Почетверте, використання продукції має відповідати ї призначенню. Інакше кажучи, якість як упорядковану сукупність властивостей, можна повністю реалізувати лише за умови відповідності застосування продукції ї цільовому призначенню" (Кардаш, 2002: 155).

У педагогічних працях під якістю, на думку О. Андрєєва, розуміють: 1) сукупність, система властивостей об'єктів і процесів; 2) єдність елементів і структури об'єктів і процесів, система якостей елементів і підсистем об'єктів і процесів; 3) основа цілісності об'єкта; 4) ієрархічна 
система властивостей або якостей частин об'єктів і процесів; 5) система властивостей або якостей частин об'єктів або процесу, що в динаміці відображає в собі якість їхнього життєвого циклу; 6) якість, що надає об'єктам властивість одиничності, визначеності, сутності; сутність $€$ корінне, внутрішнє, потенційне якості об'єкта або процесу; 7) корисність, цінність об'єктів і процесів, їх придатність або пристосованість до задоволення певних потреб або до реалізації певних цілей, норм, доктрин, ідеалів, тобто відповідність або адекватність вимогам, потребам і нормам (Андреев, 2002: 196).

Нам імпонує тлумачення поняття "якість", яке подає О. Біляковська, зазначаючи, що "ие всеосяжна інтегральна характеристика освітньої діяльності, їі результатів і основний показник діяльності й організації освітнього процесу” (Біляковська, 2017: 25).

Якість освіти, як відзначає О.Чемерис, "слід розуміти у широкому та у вузькому значенні. У широкому розумінні якість освіти розелядають як збалансовану відповідність процесу, результату і самої освітньої системи меті, потребам і соціальним нормам (стандартам) освіти; у вузькому - як перелік вимог до особистості, освітнього середовища й системи освіти, що реалізує їх на певних етапах навчання людини, якому відповідає сукупність показників" (Чемерис).

Для нас доречним $є$ визначення поняття "якість освіти" в трактуванні Г. Шандригось, яка зазначає, що "якість освіти - це сукупність ї̈ властивостей, яка обумовлює їі пристосованість до реалізації соціальних та професійних цілей з формування та розвитку особистості в аспектах ї̈ освіченості, вихованості, вираженості соиіальних, психічних, фрізичних, особистісних і спеціальних властивостей, характерних для фрахівия певної галуз" (Шандригось, 2016: 450).

Розглядаючи якість освіти, С. Jain та P. Narayan наголошують, що існують два аспекти якості освіти: якість системи освіти в цілому та якість того, що система пропонує студентам/учням (Jain, 2018: 12).

Отже, поняття "якість освіти" розглядається нами як комплексна характеристика освітнього процесу, що передбачає збалансовану відповідність процесу, результату й освітньої системи меті, потребам і соціальним стандартам освіти для формування й розвитку в особистості освіченості, вихованості та соціальних, психічних, фрізичних і духовних властивостей, що реалізується на певних етапах навчання.

3 позиції нашого дослідження актуальним видається аналіз літературних джерел стосовно з'ясування сутності поняття "якість вищої освіти".

У Законі України “Про вищу освіту" (2018) визначення якості вищої освіти відображено через результат, а саме "відповідність результатів навчання вимогам, встановленим законодавством, відповідним стандартом вищої освіти та/або договором про надання освітніх послуг".

В "Енциклопедії освіти" зазначено, що "якість вищої освіти - це комплексна характеристика, яка відображає діапазон і рівень освітніх послуг, що надаються системою освіти відповідно до інтересів особи, суспільства і держави. Якісна освіта повинна давати можливість 
Серія: Педагогічні науки. - Вип.3. - Бердянськ : БДПУ, 2019. - 453 с.

кожному індивіду залежно від його інтересів і можливостей здобувати повноцінну, безперервну освіту відповідного рівня в усіх їі формах. 3 позиції реалізації Болонського процесу існує Європейська мережа забезпечення якості (ENQA), до якої мають адаптуватися вітчизняні заклади вищої освіти" (Кремень, 2008: 1016).

Як видно з таблиці 1, в освітньо-нормативних документах дефініція “якість вищої освіти" тлумачиться неоднозначно.

\section{Визначення дефініції “якість вищої освіти” в освітньо-нормативних документах}

\begin{tabular}{|c|c|}
\hline Назва документа & Зміст поняття \\
\hline $\begin{array}{ll}\text { Методичні } & \text { рекомендації } \\
\text { щодо } & \text { розроблення } \\
\text { стандартів вищої освіти. }\end{array}$ & $\begin{array}{l}\text { Відповідність результатів навчання вимогам, } \\
\text { встановленим законодавством, відповідним } \\
\text { стандартом вищої освіти та/або договором про } \\
\text { надання освітніх послуг. }\end{array}$ \\
\hline $\begin{array}{l}\text { Національний } \quad \text { освітній } \\
\text { глосарій: вища освіта } \\
\text { (Кремень, 2011: 51). }\end{array}$ & $\begin{array}{l}\text { Характеристика вищої освіти, що відображає } \\
\text { відповідність результатів навчання, освітніх процесів } \\
\text { та інституційних умов актуальним цілям розвитку } \\
\text { особи і суспільства. }\end{array}$ \\
\hline $\begin{array}{lr}\text { Методичні } & \text { рекомендації з } \\
\text { розробки } & \text { складових } \\
\text { галузевих } & \text { стандартів } \\
\text { вищої освіти }(2013: 17) .\end{array}$ & $\begin{array}{l}\text { Сукупність якостей особи з вищою освітою, що } \\
\text { відображає ії професійну компетентність, ціннісну } \\
\text { орієнтацію, соціальну спрямованість і обумовлює } \\
\text { здатність задовольняти як особисті духовні і } \\
\text { матеріальні потреби, так і потреби суспільства. }\end{array}$ \\
\hline
\end{tabular}

У рекомендаціях “Всесвітньої декларації про вищу освіту для XXI століття: підходи та практичні заходи", прийнятих на Всесвітній конференції ЮНЕСКО в жовтні 1998 року в Парижі, зазначено, що якість вищої освіти - це її відповідність поставленим цілям, тобто якість вищої освіти не є чимось сталим, це поняття постійно змінюється відповідно до рівня розвитку суспільства та його (суспільства) потреб.

Британські науковці L. Harvey i D. Green виділяють п'ять складових поняття «якість вищої освіти»: винятковість, досконалість або послідовність, придатність до цілі, цінність за гроші, здатність до трансформаційності (Harvey, 1993: 10).

Характеризуючи якість вищої освіти, А. Токман та І. Распотнюк відзначають, що вона має "три важливі аспекти: конструктивну якість курсу профресійної підготовки, відповідну його змістовним первинним і організаційним можливостям; експлуатаційну якість, відповідну рівню реалізації навчального процесу; функціональну якість, відповідну мірі досягнення кінцевої мети професійної освіти фахівців" (Токман, 2013: 27). Це визначення будемо використовувати в нашому дослідженні.

Європейський центр з розвитку професійної освіти (CEDEFOP, 2011) трактує поняття “забезпечення якості" як види діяльності, що включають планування, впровадження, оцінювання, звітування та покращення якості, які здійснюються, щоб гарантувати, що вся освіта та навчання (зміст програм, навчальні плани, результати оцінювання та підтвердження результатів навчання тощо) відповідають вимогам якості, 
яких очікують зацікавлені сторони». Цикл забезпечення якості містить чотири окремі етапи процесу: планування (постановка чітких і реальних цілей), впровадження (визначення необхідної структури для досягнення цілей), оцінювання (розробка механізмів збирання та оцінювання інформації щодо досягнення цілей) та перегляд (оцінка результатів та внесення необхідних поправок чи змін).

Процеси забезпечення якості, як зазначено в стандартах i рекомендаціях щодо забезпечення якості в Європейському просторі вищої освіти (Standards and Guidelines for Quality Assurance in the European Higher Education Area (ESG) (2015)), передбачають дві споріднені цілі підзвітність і підвищення якості. Разом вони формують довіру до роботи вищих навчальних закладів. Успішно впроваджена система забезпечення якості постачатиме інформацію, яка зможе запевнити заклад вищої освіти i громадськість у належній якості його діяльності (підзвітність), а також даватиме поради і рекомендації щодо можливих шляхів удосконалення його роботи (підвищення якості). Отже, забезпечення якості і її підвищення $€$ взаємопов'язаними процесами. Вони здатні підтримати розвиток культури якості, до якої зможуть долучитися всі - від студентів і викладачів до керівників закладу вищої освіти.

У “Національному освітньому глосарії” поняття “забезпечення якості" визначається як "сукупність процедур, що застосовуються на інституційному (внутрішньому) та національному $і$ міжнародному (зовнішньому) рівнях для якісної реалізації освітніх / навчальних програм і присудження кваліфрікацій" (Кремень , 2011: 22). Крім того, відзначаємо, що перелік та назви процедур не визначено.

У матеріалах "Форуму організацій економічного співробітництва та розвитку" забезпечення якості професійної освіти трактується як система, що формує механізми для забезпечення моніторингу, оцінювання, підтримки та/або покращення якості діяльності закладу вищої освіти та/або програм навчання.

Випускник магістратури згідно з Дублінською моделлю універсальних характеристик компетенцій (Dublin Descriptors), що була розроблена відповідно до Болонської структури кваліфікацій, як вважає В. Сацик, повинен демонструвати знання і розуміння, які базуються чи виходять за рамки та/або поглиблюють знання і розуміння. Це зазвичай асоціюється 3 рівнем бакалавр і складає основу чи можливість для прояву оригінальності при розробці i/або застосуванні ідей, часто в рамках дослідницького контексту; застосовувати свої знання і розуміння і здатність вирішувати проблеми в нових і незнайомих сферах в рамках більш широких (міждисциплінарних) проєктів, пов'язаних з навчанням; інтегрувати знання і справлятися зі складними завданнями та формулювати судження на основі неповної чи обмеженої інформації, що передбачає врахування соціальної та етичної відповідальності, пов'язаної з використанням їх знань і суджень; поширювати свої висновки і використані для їх формулювання знання та обґрунтування в середовищі фахівців та серед не спеціалістів чітко i несуперечливо; володіти навчальними вміннями і навичками, що 
дозволяють ним продовжувати навчання значною мірою самостійно і незалежно (Сацик, 2014: 4).

Висновок. Забезпечення якості професійної підготовки майбутніх магістрів середньої освіти з фрізичної культури - це сукупність процедур та діяльності, що мають за мету гарантування та покращення ефективності надання освітніх послуг, які передбачають фрормування спеціальних знань, навчання фрізичних вправ, розвиток фрізичних здібностей та виховання морально-вольових якостей особистості, що відповідають вимогам держави та зацікавлених сторін (стейкхолдерів).

Перспективи подальших досліджень спрямовані на встановлення критеріїв та рівнів якості професійної підготовки майбутніх магістрів середньої освіти з фрізичної культури.

\section{Література}

1. Андреев А. А. Педагогика высшей школы. Новый курс / А. А. Андреев. М. : Московский международный институт эконометрики, информатики, финансов и права, 2002. - 264 с.

2. Біляковська О. О. Якість освіти: до генези поняття / О. О. Біляковська // Збірник наукових праць. Педагогічні науки. - Херсонський державний університет, 2017. - Вип. LXXVI (Том1). - С.24-29.

3. Енциклопедія освіти / Акад. пед. наук України ; гол. ред. В. Г. Кремень. - К. : Юрінком Інтер, 2008. - 1040 с.

4. Кардаш В. Я. Товарна інноваційна політика: Підручник / В. Я. Кардаш, І. А. Павленко, О. К. Шафалюк. - К. : КНЕУ, 2002. - 266 с.

5. Методичні рекомендації з розробки складових галузевих стандартів вищої освіти (компетентнісний підхід) / В. Л. Гуло, К. М. Левківський, Л. О. Котоловець та ін.. - К.: Інститут інноваційних технологій і змісту освіти МОН України, 2013. - 127 с.

6. Методичні рекомендації щодо розроблення стандартів вищої освіти [Електронний ресурс] Режим доступу: https://mon.gov.ua/storage/app/media/vishchaosvita/rekomendatsii-1648.pdf.

7. Національний освітній глосарій: вища освіта / Авт.-уклад.: І. І. Бабин, А. А. Гармаш, В.П. Головенкін та ін.; за редакцією Д. В. Табачника і В. Г. Кремня. К.: ТОВ “Видавничий дім “Плеяди”, 2011. - 76 с.

8. Сацик В. В. Дублінська модель універсальних характеристик компетенцій (Дублінські дескриптори) / В. Сацик // Освітні тренди: сайт про сучасні тенденції розвитку освіти. - 2014. - С. 1-6.

9. Столяров В.И. Теория и методология современного фризического воспитания: состояние разработки и авторская концепция : монография / В. И. Столяров. - Киев : Олимп. лит., 2015. - 704 с.

10. Сучасний словник іншомовних слів: близько 20 тис. слів і словосполучень / укл. : О. І. Скопненко, Т. В. Цимбалюк.-Київ : Довіра, 2006. - 796 с.

11. Токман А. Сутність і структура поняття «якість освіти у ВНЗ» у педагогічній літературі / А. Токман, І. Распошнюк // Освіта на Луганщині. - 2013. №1. - C. 25-29.

12. Чемерис О. А. Якість освіти як загальна тенденція європейської інтеграції [Електронний ресурс] / О. А. Чемерис. - Режим доступу : http://studentam.net.ua/content/view/7711/97/

13. Шандригось Г. А. До проблеми якості професійної підготовки майбутніх вчителів фізичної культури/ Г. А. Шандригось, В.І.Шандригось // Матеріали XVI Міжнародної науково-практичної конференція «Фізична культура, спорт та 
здоров'я: стан і перспективи в умовах сучасного українського державотворення в контексті 25-річчя Незалежності України», Харків. - 2016. С. 449-452 .

14. Шипилина Л. А. Качество профессионального образования : к вопросу философрско-методологических оснований / Л. А. Шипилина // Право и образование. 2007. - №10. - С. 44-57.

15. Harvey L. Defining quality / L. Harvey, D. Green // Assessment and Evaluation in Higher Education. - 1993. - V. 18 (1). - P. 9-34.

16. Jain C. Quality of Secondary Education in India:Concepts, Indicators, and Measurement/ C. Jain, P. Narayan .- Springer Nature Singapore Pte Ltd. 2018. - 225 p.

\section{References}

1. Andreev A. A. Pedagogika vysshej shkoly. Novyj kurs / A. A. Andreev. - M. : Moskovskij mezhdunarodnyj institut jekonometriki, informatiki, finansov i prava, 2002. 264 s. [in Russian].

2. Biliakovska O. O. Yakist osvity: do henezy poniattia / O. O. Biliakovska // Zbirnyk naukovykh prats. Pedahohichni nauky. - Khersonskyi derzhavnyi universytet, 2017. - Vyp. LXXVI (Tom1). - S.24-29 [in Ukrainian].

3. Entsyklopediia osvity / Akad. ped. nauk Ukrainy ; hol. red. V. H. Kremen. K. : Yurinkom Inter, 2008. - 1040 s. [in Ukrainian].

4. Kardash V. Ya. Tovarna innovatsiina polityka: Pidruchnyk / V. Ya. Kardash, I. A. Pavlenko, O. K. Shafaliuk. - K. : KNEU, 2002. - 266 s. [in Ukrainian].

5. Metodychni rekomendatsii z rozrobky skladovykh haluzevykh standartiv vyshchoi osvity (kompetentnisnyi pidkhid) / V. L. Hulo, K. M. Levkivskyi, L. O. Kotolovets ta in.. - K.: Instytut innovatsiinykh tekhnolohii i zmistu osvity MON Ukrainy, 2013. - 127 s. [in Ukrainian].

6. Metodychni rekomendatsii shchodo rozroblennia standartiv vyshchoi osvity [Elektronnyi resurs] Rezhym dostupu: https://mon.gov.ua/storage/app/media/vishchaosvita/rekomendatsii-1648.pdf.

7. Natsionalnyi osvitnii hlosarii: vyshcha osvita / Avt.-uklad.: I. I. Babyn, A. A. Harmash, V.P. Holovenkin ta in.; za redaktsiieiu D. V. Tabachnyka i V. H. Kremnia. - K.: TOV "Vydavnychyi dim "Pleiady", 2011. - 76 s. [in Ukrainian].

8. Satsyk V. V. Dublinska model universalnykh kharakterystyk kompetentsii (Dublinski deskryptory) / V. Satsyk // Osvitni trendy: sait pro suchasni tendentsii rozvytku osvity. 2014. - S. 1-6. [in Ukrainian].

9. Stoljarov V.I. Teorija i metodologija sovremennogo fizicheskogo vospitanija : sostojanie razrabotki i avtorskaja koncepcija : monografija / V.I. Stoljarov. - Kiev : Olimp. lit., 2015. - 704 s. [in Ukrainian].

10. Suchasnyi slovnyk inshomovnykh sliv: blyzko 20 tys. sliv i slovospoluchen / ukl. : O.I. Skopnenko, T.V. Tsymbaliuk.-Kyiv : Dovira, 2006. - 796 s. [in Ukrainian].

11. Tokman A. Sutnist i struktura poniattia "yakist osvity u VNZ» u pedahohichnii literaturi / A. Tokman, I. Rasposhniuk // Osvita na Luhanshchyni, 2013. №1. - S. 25 - 29 [in Ukrainian].

12. Chemerys O. A. Yakist osvity yak zahalna tendentsiia yevropeiskoi intehratsii [Elektronnyi resurs] / O. A. Chemerys. - Rezhym dostupu : http://studentam.net.ua/content/view/7711/97/

13. Shandryhos H. A. Do problemy yakosti profesiinoi pidhotovky maibutnikh vchyteliv fizychnoi kultury/ H. A. Shandryhos, V. I. Shandryhos // Materialy XVI Mizhnarodnoi naukovo-praktychnoi konferentsiia «Fizychna kultura, sport ta zdorovia: stan i perspektyvy $v$ umovakh suchasnoho ukrainskoho derzhavotvorennia $v$ konteksti 25-richchia Nezalezhnosti Ukrainy», Kharkiv. - 2016. S. 449-452 [in Ukrainian]. 
14. Shipilina L. A. Kachestvo professional'nogo obrazovanija : k voprosu filosofsko-metodologicheskih osnovanij / L. A. Shipilina // Pravo i obrazovanie. - 2007. №10. - S. 44-57 [in Russian].

15. Harvey L. Defining quality / L. Harvey, D. Green // Assessment and Evaluation in Higher Education. - 1993. - V. 18 (1). - P. 9-34. [in England].

16. Jain C. Quality of Secondary Education in India:Concepts, Indicators, and Measurement/ $\underline{C}$. Jain, P. Narayan .- Springer Nature Singapore Pte Ltd. $-2018 .-225$ p. [in India].

\section{АНОТАЦІЯ}

Забезпечення якості професійної підготовки майбутніх фрахівців (профресіоналів) є нагальною проблемою та обумовлюється різними факторами, серед яких виділяються забезпечення якості мети, якості освітнього процесу $i$ якості результату. У цих умовах важливе значення має розуміння базових понять дослідження.

Mema cmammi - здійснити теоретичний аналіз дефініції “забезпечення якості професійної підготовки" для майбутніх магістрів середньої освіти $з$ фозичної культури.

Методи дослідження: аналіз літературних джерел та документів; метод системного аналізу; метод порівняння $і$ зіставлення; метод функціонально-структурного аналізу.

Для обгрунтування дефініції "забезпечення якості профресійної підготовки" для майбутніх магістрів середньої освіти з фрізичної культури вважаємо за доцільне з'ясувати сутність понять "якість", "якість освіти", "якість вищої освіти", які є ключовими для вказаного визначення.

Поняття "якість освіти" розглядається нами як комплексна характеристика освітнього процесу, що передбачає збалансовану відповідність процесу, результату й освітньої системи меті, потребам i соціальним стандартам освіти для формування і розвитку в особистості освіченості, вихованості та певних соціальних, психічних, фрізичних і духовних властивостей, що реалізується на певних етапах навчання.

Проаналізовано трактування поняття “забезпечення якості" викладене Європейським чентром з розвитку професійної освіти та у стандартах $i$ рекомендаціях щодо забезпечення якості в Європейському просторі вищої освіти. Охарактеризована Дублінська модель універсальних характеристик компетенцій (Dublin Descriptors) випускників магістратури.

Вважаємо за доцільне констатувати, що забезпечення якості професійної підготовки майбутніх магістрів середньої освіти з фрізичної культури - це сукупність процедур та діяльності, що мають за мету гарантування та покращення ефективності надання освітніх послуг, які передбачають формування спеціальних знань, навчання фізичних вправ, розвиток фрізичних здібностей та виховання морально-вольових якостей особистості відповідно до вимог держави та зацікавлених сторін (стейкхолдерів).

Ключові слова: якість, якість освіти, якість вищої освіти, забезпечення якості профессійної підготовки майбутніх магістрів середньої освіти з фрізичної культури. 